\title{
Review
}

Pharmacology

\section{Drug Therapy in Stroke: From Preclinical to Clinical Studies}

\author{
Harjeet Kaur Ajay Prakash Bikash Medhi \\ Department of Pharmacology, Postgraduate Institute of Medical Education and Research, Chandigarh, India
}

\author{
Key Words \\ Ischemic stroke · Neuroprotection · Phase III trial · Cerebral \\ ischemia $\cdot$ Clinical trial
}

\begin{abstract}
Background: Stroke is one of the major challenges to health and the reason for increasing disability-adjusted life years. Despite tremendous progress in preclinical studies, none of the treatment options has proven efficacious in clinical studies. The basic aim of neuroprotection is to interfere with the events of the ischemic cascade, halt the pathological processes and prevent the death of vulnerable nerve cells in the ischemic penumbra. Summary: This review will provide a brief overview of the current understanding of stroke, including the global epidemiology of stroke, its pathophysiology, the targeting of specific pathways and the success and failure of preclinical as well as clinical studies, and it will discuss the emerging targets for novel therapeutic strategies under investigation. Key Messages: New advancing investigational drugs for the prevention and treatment of stroke are on the way and may someday give hope to neuroscientists and clinicians. A novel approach should adopt preclinical testing, advance the understanding of the pathophysiology of stroke and make it possible to translate it from bench to bedside. We should learn from the past failures and move on with more enthusiasm.

(c) 2013 S. Karger AG, Basel
\end{abstract}

(2013 S. Karger AG, Basel

0031-7012/13/0926-0324\$38.00/0

\section{Introduction}

Stroke is one of the most devastating neurological conditions. It is the 3rd most common cause of death after coronary heart disease and cancer in developed countries. It is the 2 nd most common cause of death above the age of 60 years, and the 5th most common cause in people aged 15-59 years [1]. Stroke or cerebral ischemia or a cerebral vascular accident is the sudden death of brain cells due to inadequate blood flow [2]. The risk for ischemic stroke is very high in cigarette smokers and diabetic patients at all ages, but this risk is most prominent in case of diabetes before 55 years of age in Black people and before 65 years of age in White people [3]. Stroke also increases the disability-adjusted life years (DALY) and makes the life of patients miserable. The burden of DALY was around 38 million in 1990 and will have increased to 61 million in 2020 worldwide due to stroke. It has been predicted that stroke will have moved from the 6th most common cause of DALY lost to the 4th in 2020 [4]. Despite widely available treatment options, still prevalence rates of stroke are high due to lower efficacy of drugs in clinical studies.

\section{Pathophysiology}

Cerebral ischemia may be defined as a condition of reduction in blood supply to the brain which leads to decreased availability of glucose and oxygen to brain cells.

\section{KARGER}

E-Mail karger@karger.com

www.karger.com/pha
Bikash Medhi

Department of Pharmacology

Postgraduate Institute of Medical Education and Research

Sector 12, Research Block B, Room No. 4043, Chandigarh 160012 (India)

E-Mail drbikashus@yahoo.com 


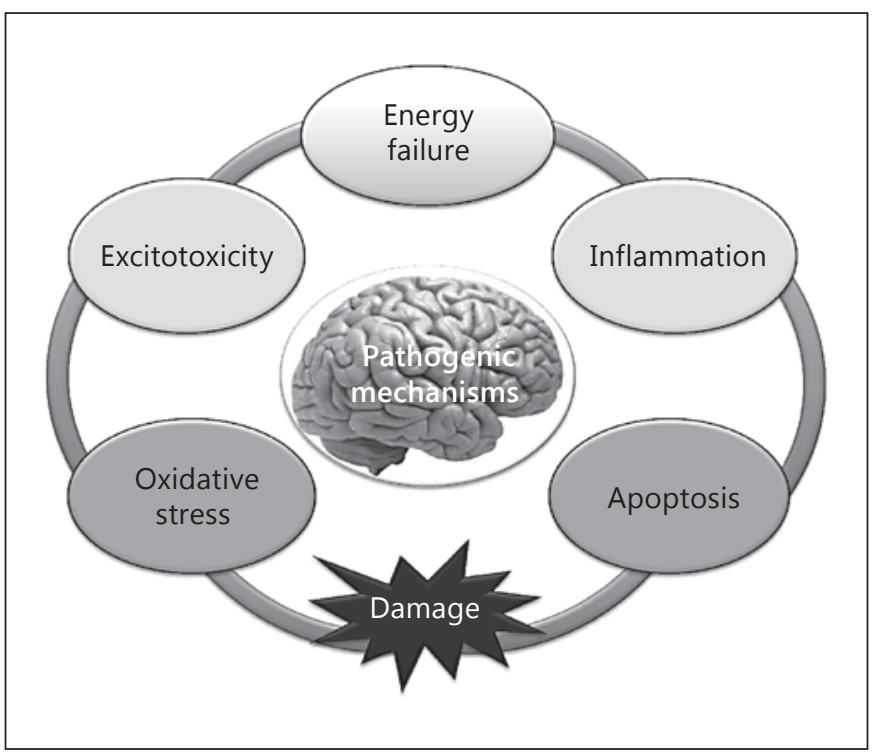

Fig. 1. Main targets of stroke.

As energy is essential to maintain ionic gradient brain homeostasis, the shortage of energy interrupts the energy-dependent processes in the brain. Stroke is mainly of two types: (1) ischemic stroke, caused when blood vessels supplying the brain are blocked by clot formation (50$85 \%$ of all strokes worldwide are ischemic), and (2) hemorrhagic stroke, caused when blood vessels become weak and their rupture leads to leakage of blood (13-15\% of all strokes worldwide). The pathophysiology of stroke is complex and involves numerous processes including energy failure, loss of ion homeostasis, overload of intracellular calcium ion $\left(\mathrm{Ca}^{2+}\right)$ concentrations, excitotoxicity, activation of free radicals, release of cytokines, disruption to the blood-brain barrier (BBB), activation of glial cells and inflammation; these series of cascading events are well interrelated and coordinated, and they ultimately lead to necrosis and apoptosis. These events are not strictly in order but show overlaps. The extent of damage usually depends on the duration, severity and site of ischemia. Neurons require a constant supply of glucose and oxygen to conduct impulse transmission in order to maintain the ionic gradients across the membrane [5] (fig. 1).

The brain uses a lot of energy to synthesize ATP by oxidative phosphorylation and to regulate and maintain ionic gradient homeostasis. When the blood flow is interrupted, inhibition of mitochondrial ATP synthesis occurs, which permits the influx of $\mathrm{Na}^{+}$and the efflux of $\mathrm{K}^{+}$ ions from the cell [6]. Hence, this disturbs the whole ho- meostasis and leads to cell membrane depolarization. The elevated intracellular levels of $\mathrm{Ca}^{2+}, \mathrm{Na}^{+}$and ADP cause mitochondria to release a deleterious amount of reactive oxygen species, which causes oxidative damage. Various cytokines act on astrocytes and microglia and activate the formation of matrix metalloproteinases. Once stimulated, it causes disruption of the BBB, leading to vasogenic edema and hemorrhage, damaging capillaries, collagen and laminins in the basal lamina, which further degrades the composition of the vascular wall and enhances BBB permeability, causing neuronal death by necrosis as well as apoptosis [7] (fig. 2).

\section{Therapeutic Management of Stroke}

\section{Challenges in Stroke Treatment}

Despite tremendous progress in preclinical studies, none of the treatment options has proven efficacious in clinical studies. Some of the molecular events that can be targeted by neuroprotectants include: glutamate release, glutamate receptor activation, excitotoxicity, $\mathrm{Ca}^{2+}$ influx into cells, mitochondrial dysfunction, activation of many intracellular enzymes, free radical production, nitric oxide production, inflammation, necrosis and apoptosis.

In spite of advances in our understanding of the pathophysiology of cerebral ischemia, therapeutic options for acute ischemic stroke remain very limited. Only one drug is approved for clinical use in the thrombolytic treatment of acute ischemic stroke in the USA, and that is intravenous administration of recombinant tissue plasminogen activator (rt-PA). When delivered within $3 \mathrm{~h}$ after symptom onset, rt-PA reduces neurological deficits and improves functional outcome in stroke patients. However, this improvement in recovery is achieved at the expense of an increased incidence of symptomatic intracranial hemorrhage, which occurs in approximately $6 \%$ of patients. Furthermore, the large majority of patients with acute ischemic stroke is not able to reach a hospital within $3 \mathrm{~h}$ after stroke onset, and most of them therefore do not receive rt-PA treatment [8]. Consequently, successful treatment of acute ischemic stroke remains one of the major challenges in clinical practice.

More than 100 neuroprotective agents have shown neuroprotective effects on focal ischemic stroke in preclinical studies, but none has proven to be beneficial in clinical studies. However, the failed trials of the past have 
Fig. 2. Basic cascade of stroke. ROS = Reactive oxygen species; TNF- $\alpha=$ tumor necrosis factor- $\alpha$; IL- $\beta=$ interleukin $-\beta$; MMP = matrix metalloproteinase; $\mathrm{ER}=$ endoplasmic reticulum.

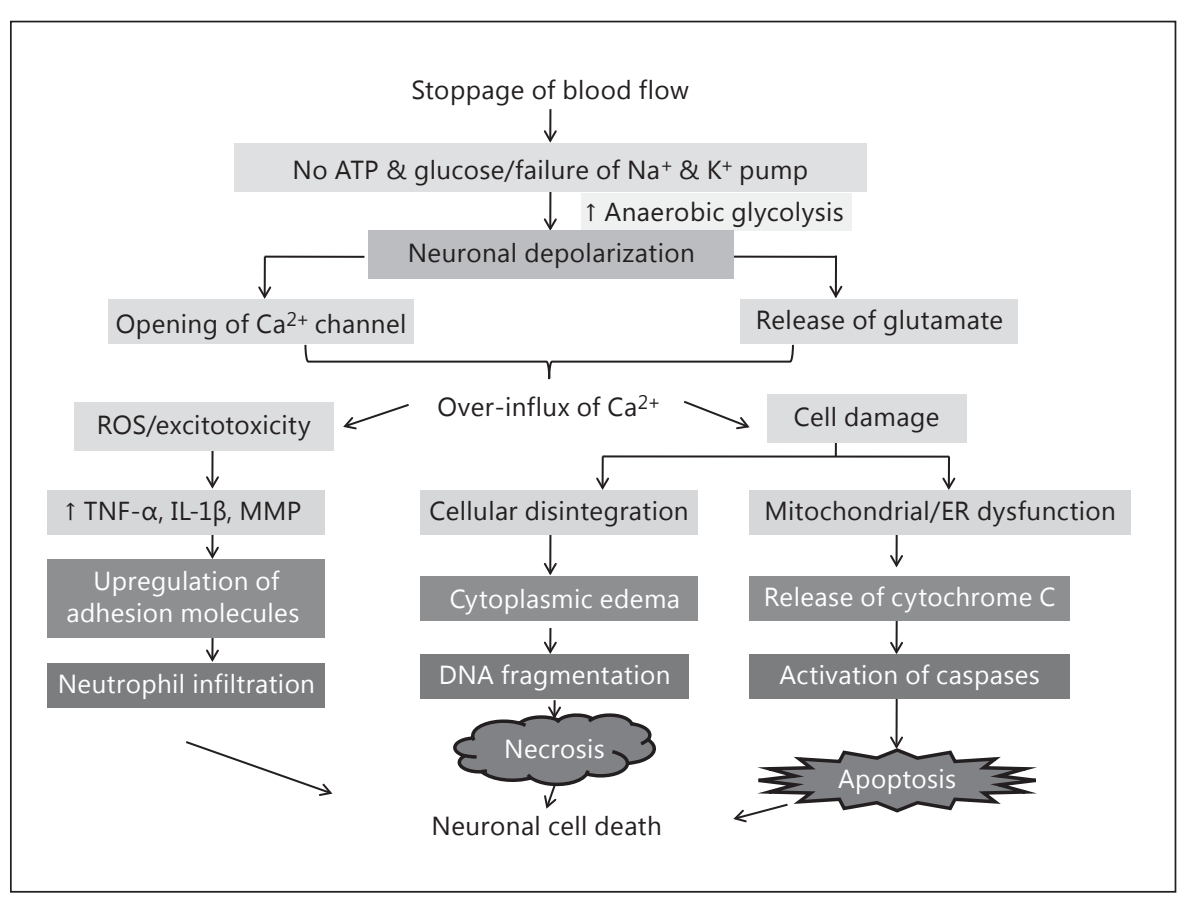

greatly increased our understanding of the fundamental biology of ischemic brain injury and have laid a strong foundation for future development [9].

\section{Drug Development Status}

A recent view has been that 'everything works in animals but nothing works in humans', as successes of clinical trials declined over the successes of preclinical studies. Neuroprotective drugs for stroke were first initiated during the 1980s and are still in development. The basic aim of neuroprotection is to interfere with the events of the ischemic cascade, to halt the pathological processes and to prevent the death of vulnerable nerve cells in the ischemic penumbra. Despite the positive results from experimental animal studies, almost all clinical trials of neuroprotective therapies to date have not shown any success $[10,11]$.

\section{Clinical Trials Failed: Why?}

The sweet success of neuroprotective agents in animal studies and the bitter aftertaste in clinical studies of stroke have recently been a major topic of discussion in research. Reasons for such a fundamental failure may be [12]:
(1) Time window: preclinical studies have used very short time windows for drug administration, whereas longer time windows are permitted in clinical trials

(2) Target: preclinical studies target the ischemic penumbra, whereas clinical trials do not

(3) Duration: the optimal duration of neuroprotectant administration is unknown

(4) Outcome: preclinical studies use different outcome measures such as infarct size to judge therapeutic efficacy, whereas clinical trials use clinical and functional end points measured by the modified Rankin Scale and the Barthel index

(5) Preclinical studies have relied on early outcomes, whereas clinical trials rely on late assessments

(6) Diversity of stroke types: most of the preclinical studies use middle cerebral artery occlusion as a model of ischemic stroke and therefore do not mimic the pathophysiological heterogeneity of different stroke types, as well as their extent, duration of ischemia and severity; by contrast, human studies include patients with a broad pathophysiological heterogeneity

(7) Differences in comorbidities: most of the experimental models use young healthy rodents which are not exposed to other medications, whereas stroke patients often suffer from several severe comorbidities (prior ischemic attack, cardiovascular diseases, etc.) and have premedication with other drugs 


\section{Preclinical and Clinical Studies}

In preclinical studies, over a thousand of potential neuroprotective therapies have been used to target some of the molecular events, with many of these shown to be protective. To date, various cascades of events which lead to the pathophysiology of stroke have been targeted to reduce its deteriorating effect [13]. Different therapeutic approaches tried on animals as well as in clinical trials are discussed below and summarized in table 1 .

\section{Antithrombotic Agents}

Preclinical Output

Heparin. Heparin is widely used for the treatment of acute stroke. Intravenous heparin sodium could be very effective in the earliest treatment of acute nonlacunar hemispheric cerebral infarction, but at the same time it also increases the incidence of intracranial symptomatic brain hemorrhages [13]. An in vitro study of ultra-lowmolecular-weight heparin which was carried out on cultured PC12 cells exposed to Earle's solution containing sodium dithionite showed significant inhibition of cell damage induced by oxygen glucose deprivation. Heparin also exerted neuroprotective effects by significantly reducing the infarct volume in rats with focal cerebral ischemic injury at doses of 0.5 and $1.0 \mathrm{mg} / \mathrm{kg}$ [14] and partly by improving energy metabolism, inhibiting apoptosis and attenuating the inflammatory reaction [15].

Enoxaparin. Intravenous administration of enoxaparin significantly reduces infarct size, improves the neuroscore in both permanent and transient focal ischemia in rats, exhibits a large therapeutic window of at least $5 \mathrm{~h}$ and is devoid of major hemorrhagic risk [16].

\section{Clinical Output}

Heparin. In an observational study, ultra-slow continuous intravenous infusion of unfractionated heparin can has significantly reduced the neurological deficit score of patients with progressive cerebral infarction [17].

Enoxaparin. In a phase IV study of enoxaparin, longterm neurological outcome improved and the frequency of symptomatic intracranial hemorrhages decreased in patients for venous thromboembolism prophylaxis (blood clot forming within a vein) [18].

\section{Antiplatelet Agents}

Preclinical Output

Cilostazol. Recent animal studies showed a neuroprotective role of cilostazol in transient focal cerebral is- chemia against ischemic brain injury and hemorrhagic transformation [19].

Eptifibatide. Preclinical data from an embolic mouse model demonstrated that the combination of a fibrinolytic agent with eptifibatide, a glycoprotein (GP)IIb/IIIa inhibitor, increased the efficiency in dissolving an embolus, decreased the infarct volume, and improved microvascular patency compared with a fibrinolytic agent alone. Treatment with rt-PA and a GPIIb/IIIa antagonist reduced perfusion deficits and significantly enhanced cortical perfusion [20].

Abciximab. In preclinical studies, abciximab was found to be protective against ischemic stroke [10].

\section{Clinical Output}

Aspirin and Cilostazol. In a randomized, double-blind noninferiority trial, cilostazol was found to be more feasible, efficacious and safe than aspirin in acute ischemic stroke [21] and could be an effective neuroprotective agent in patients with noncardioembolic stroke [22]. In a multicenter, randomized, double-blind, placebo-controlled trial, patients were randomly assigned to receive either placebo or $100 \mathrm{mg}$ cilostazol twice a day as well as $100 \mathrm{mg}$ aspirin a day. Cilostazol decreased the transcranial Doppler pulsatility index at 90 days from baseline compared with placebo in acute lacunar infarction (lacunar infarcts are a frequent type of stroke caused mainly by cerebral small-vessel disease). This result may be related to pleiotropic effects such as vasodilation, beyond its antiplatelet activity [23]. A phase III study of cilostazol-aspirin in recurrent stroke with intracranial artery stenosis was completed and its results are still awaited [24].

Eptifibatide. Intravenous eptifibatide is an FDA-approved drug for the treatment of blood clots causing heart attack and chest pain. Eptifibatide inhibits platelet aggregation by blocking activated platelets from binding fibrinogen. The CLEAR (Study of the Combination Therapy of rt-PA and Eptifibatide to Treat Acute Ischemic Stroke) showed the safety of the use of a combination of low-dose rt-PA and a GPIIb/IIIa antagonist (eptifibatide) in acute ischemic stroke patients who were treated within $3 \mathrm{~h}$ after symptom onset. The safety profile of the combination regimens was excellent when using $0.6 \mathrm{mg} / \mathrm{kg} \mathrm{rt}-$ PA plus eptifibatide versus standard-dosed rt-PA. The efficacy of this trial has led to a phase III clinical trial [25]. The CLEAR-ER, a phase II trial, begun in July 2009 to determine whether intravenous treatment with a medium dose of rt-PA plus eptifibatide started within $3 \mathrm{~h}$ after symptom onset might have a better outcome than standard (intravenous) treatment with rt-PA alone. Data on 
the primary outcome measure were collected in October 2012 and the results are still awaited [26].

Abciximab. A phase III trial was terminated prematurely after having enrolled 808 patients in all cohorts, at the recommendation of an independent safety and efficacy monitoring board due to an unfavorable benefit-risk profile, as there were increased rates of symptomatic and fatal intracranial hemorrhage in the primary and wakeup cohorts [27].

Aspirin and Clopidogrel. The risk of recurrent stroke and the risk of major hemorrhage was high with dual antiplatelet therapy as compared with aspirin alone. Even dual therapy did not reduce the mortality rate (77 deaths in the group receiving aspirin alone vs. 113 in the group receiving dual antiplatelet therapy) [28]. A phase IV study aiming to compare the preventive effect of triflusal and clopidogrel in ischemic stroke patients based on the cytochrome P450 2C19 polymorphism was started in March 2010. About 795 patients have been enrolled so far and the study is estimated to be completed in January 2015 [29].

\section{Thrombolytic Agents}

Preclinical Output

$t$-PA and Streptokinase. Various experimental studies have shown the neuroprotective potential of t-PA and streptokinase [10].

\section{Clinical Output}

$t-P A$. Intravenous injection of rt-PA is the only treatment that has been approved for acute ischemic stroke by the FDA (in 1996). This was based on the results of clinical research on rt-PA conducted by the National Institute of Neurological Disorders and Stroke in 1995, and rt-PA is the only drug approved by the FDA that has to be injected within $3 \mathrm{~h}$ after onset [30], in spite of an increased risk of symptomatic intracerebral hemorrhage [31].

$t-P A$ and Urokinase. Treatment with conventionaldose intravenous rt-PA and its combination with intraarterial urokinase were safe and feasible in patients. This strategy achieved high rates of complete arterial recanalization and good functional outcomes [32]. The administration of urokinase within $24 \mathrm{~h}$ after onset of stroke significantly improved the clinical outcomes as compared with a control group, which agreed with results from previous reports on the action of thrombolytic agents. Urokinase also showed a significant effect (in terms of the increase in cerebral blood flow to ischemic brain tissues and prevention of the spread of cerebral thrombi) if administered to patients even more than $24 \mathrm{~h}$ after the onset of strokes. Only 2 out of 93 patients in the urokinase treatment group showed minor hemorrhagic transformation. This value is noticeably lower than that shown in previous studies. However, mild hemorrhage in the gastrointestinal tract and hemorrhage in the oral cavity that could be readily controlled by drugs were shown in 8 of the 93 patients [33].

\section{Calcium Channel Blockers}

Preclinical Output

Nimodipine. The results of a systematic review of experimental studies did not show convincing evidence to begin trials with nimodipine on a large number of patients. The review included 20 studies out of 225 identified articles. The methodological quality of the studies was poor. Among the included studies, 50\% (10 studies) were in favor of nimodipine and showed statistically significant effects [34].

\section{Clinical Output}

Nimodipine. In a Cochrane review, the authors reported around 19 studies which assessed the effects of a calcium antagonist (nimodipine) in patients with ischemic stroke. No difference in death rates or survival free of disability was observed between patients who received nimodipine and those who did not. There was no evidence that giving nimodipine (calcium antagonists) after acute ischemic stroke could save lives or reduce disability [35].

\section{Antioxidants}

Preclinical Output

NXY-059. NXY-059 was found to be neuroprotective in animal models by reducing infarct size [36, 37].

Ebselen. Ebselen showed an antioxidant effect by repressing lipid peroxidation and inhibiting inducible nitric oxide synthase protein expression in cerebral cortex homogenate in stroke-prone, spontaneously hypertensive rats [38].

Tirilazad. A systematic review of studies on tirilazad demonstrated its efficacy in animal models of focal ischemia by reducing the infarct volume by $29.2 \%$ and improving the neurobehavioral score by $48.1 \%$ [39].

Edaravone. Edaravone significantly reduced the infarct volume and improved the neurological deficit scores at $24 \mathrm{~h}$ after reperfusion in transient focal ischemia in mice [40]. Edaravone significantly reduced oxidative cell death in both HT22 neuronal cells and primary rat astrocytes [41]. 


\section{Clinical Output}

NXY-059. In a randomized, double-blind, placebo-controlled trial involving 1,722 patients, administration of NXY-059 within $6 \mathrm{~h}$ after the onset of acute ischemic stroke significantly improved the primary outcome (reduced disability at 90 days), but it did not significantly improve other outcome measures, including neurologic functioning as measured by the National Institutes of Health Stroke Scale score [42]. In a phase III trial, NXY-059 was shown to be ineffective in the treatment of acute ischemic stroke within $6 \mathrm{~h}$ after the onset of symptoms [43].

Ebselen. A phase III trial of 394 patients was started in 2001; either $150 \mathrm{mg}$ ebselen or placebo was administered to patients twice per day within $24 \mathrm{~h}$ after stroke, and the patients were treated continuously for 14 days. The results are not available yet [44].

Tirilazad. Tirilazad did not show a significant effect on infarct volume in patients with acute ischemic stroke [45].

Edaravone. Edaravone ameliorated the size of ischemic stroke lesions and neurological deficits in patients with small-vessel occlusion, i.e. lacunar infarction, within 1 year, while there were no significant differences in outcome after 1 year [46]. In a study comparing edaravone and citicoline in acute ischemic stroke, edaravone was more effective with a better neurological outcome at 3 months than citicoline [47].

\section{GABA Agonists}

Preclinical Output

Clomethiazole. Clomethiazole was protective at plasma concentrations of $6.1 \mu \mathrm{mol} / \mathrm{l}$ and above and at 3.5 $\mu \mathrm{mol} / \mathrm{l}$ and above, respectively. Therefore, clomethiazole was neuroprotective in both global and focal ischemia models at plasma concentrations known to be well tolerated by stroke patients [48]. Clomethiazole also provided significant neuroprotection with limited functional preservation in a model of global ischemia [49].

\section{Clinical Output}

Clomethiazole. In the CLASS-I (Clomethiazole Acute Stroke Study in Ischemic Stroke), a randomized, doubleblind, binational (USA and Canada), multicenter, placebo-controlled study, a total of 1,198 patients with major ischemic stroke and a combination of limb weakness, higher cortical dysfunction and visual field deficits were randomly assigned to clomethiazole $(68 \mathrm{mg} / \mathrm{kg}$ intravenously over $24 \mathrm{~h}$ ) treatment or placebo. The results suggest that clomethiazole has no effect on disability, stroke deficit or infarct volume in patients with major ischemic stroke [50].

Drug Therapy and Stroke

\section{Competitive NMDA Antagonists}

Preclinical Output

CGS 19755. CGS 19755 has shown to be effective in preclinical studies at a dose of $40 \mathrm{mg} / \mathrm{kg}$ by reducing infarct size by approximately $50 \%$ [51].

\section{Clinical Output}

CGS 19755. After safe and effective results of a phase II study, two pivotal phase III, double-blind, randomized, placebo-controlled, parallel-design ischemic stroke trials enrolled a total of 567 patients to which a single intravenous $1.5 \mathrm{mg} / \mathrm{kg}$ dose of CGS19755 was administered within $6 \mathrm{~h}$ after stroke onset. The trial was suspended on the advice of the independent Data Safety Monitoring Board (DSMB) because of high mortality rates of $22 \%$ in the CGS 19755 group and of $17 \%$ in the placebo-treated group. Thus, the high mortality rate particularly within the first 30 days, and in patients with severe stroke, suggests that the drug might have a neurotoxic effect. So, these trials were also terminated prematurely on the advice of the independent DSMB, based on an overall mortality imbalance $[52,53]$.

\section{Noncompetitive NMDA Antagonists}

Preclinical Output

Aptiganel (CNS-1102). Aptiganel was effective in a rat model of focal ischemia by providing a shield to cerebral gray matter as well as white matter from ischemic injury and by preventing the degeneration of myelin and axons [54].

MK-801. MK-801 only improved normothermic animals, whereas hypothalamic damage with hyperthermia masked the neuroprotective effect of MK-801 in focal cerebral ischemia [55]. MK-801-treated rats had shown significantly $(\mathrm{p}<0.05)$ better neurological outcome and good recovery [56].

\section{Clinical Output}

Aptiganel. Aptiganel was not found to be efficacious in a phase II/III randomized controlled trial involving 628 patients with hemispheric ischemic stroke. The trial was suspended by the sponsor and the independent DSMB because of both a lack of efficacy and a potential imbalance in mortality [57].

\section{AMPA Antagonists}

Preclinical Output

ZK 200775. ZK 200775 (MPQX) significantly reduced infarct size in a transient middle cerebral artery occlusion model of ischemic stroke [58]. 
Table 1. Summary of neuroprotective agents in preclinical and clinical studies

\begin{tabular}{|c|c|c|c|c|c|}
\hline No. & Compound & Precl & linical output & Clini & ical output \\
\hline 1 & $\begin{array}{l}\text { Antithrombotic agents } \\
\text { (i) Heparin } \\
\text { (ii) Enoxaparin }\end{array}$ & $\begin{array}{l}\text { (i) } \\
\text { (ii) }\end{array}$ & $\begin{array}{l}\text { effective }[13-15] \\
\text { effective }[16]\end{array}$ & $\begin{array}{l}\text { (i) } \\
\text { (ii) }\end{array}$ & $\begin{array}{l}\text { effective [17] } \\
\text { phase IV: effective [18] }\end{array}$ \\
\hline 2 & $\begin{array}{l}\text { Antiplatelet agents } \\
\text { (i) } \text { Clopidogrel } \\
\text { (ii) Cilostazol } \\
\text { (iii) } \text { Abciximab } \\
\text { (iv) Eptifibatide }\end{array}$ & $\begin{array}{l}\text { (ii) } \\
\text { (iii) } \\
\text { (iv) }\end{array}$ & $\begin{array}{l}- \\
\text { effective [19] } \\
\text { effective [10] } \\
\text { effective [20] }\end{array}$ & $\begin{array}{l}\text { (i) } \\
\text { (ii) } \\
\text { (iii) } \\
\text { (iv) }\end{array}$ & $\begin{array}{l}\text { phase IV: ongoing [29] } \\
\text { phase III: results awaited [24] } \\
\text { phase III: terminated [27] } \\
\text { phase II: results awaited [26] }\end{array}$ \\
\hline 3 & $\begin{array}{l}\text { Thrombolytic agents } \\
\text { (i) t-PA }\end{array}$ & (i) & effective [10] & (i) & phase III: effective $[30,31]$ \\
\hline 4 & $\begin{array}{l}\text { Calcium channel blockers } \\
\text { (i) Nimodipine }\end{array}$ & (i) & effective [34] & (i) & ineffective [35] \\
\hline 5 & 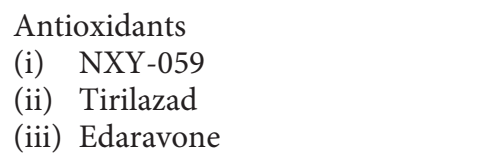 & $\begin{array}{l}\text { (i) } \\
\text { (ii) } \\
\text { (iii) }\end{array}$ & $\begin{array}{l}\text { effective }[36,37] \\
\text { effective }[39] \\
\text { effective }[40,41]\end{array}$ & $\begin{array}{l}\text { (i) } \\
\text { (ii) } \\
\text { (iii) }\end{array}$ & $\begin{array}{l}\text { phase III: ineffective [43] } \\
\text { ineffective }[45] \\
\text { effective }[46,47]\end{array}$ \\
\hline 6 & $\begin{array}{l}\text { GABA agonist } \\
\text { (i) Clomethiazole }\end{array}$ & (i) & effective $[48,49]$ & (i) & ineffective [50] \\
\hline 7 & $\begin{array}{l}\text { Competitive NMDA antagonists } \\
\text { (i) CGS } 19755\end{array}$ & (i) & effective [51] & (i) & phase III: ineffective [53] \\
\hline 8 & $\begin{array}{l}\text { Noncompetitive NMDA antagonists } \\
\text { (i) Aptiganel } \\
\text { (ii) MK- } 801\end{array}$ & $\begin{array}{l}\text { (i) } \\
\text { (ii) }\end{array}$ & $\begin{array}{l}\text { effective }[54] \\
\text { effective }[55,56]\end{array}$ & & phase III: ineffective [57] \\
\hline 9 & $\begin{array}{l}\text { AMPA antagonists } \\
\text { (i) ZK } 200775 \\
\text { (ii) YM872 }\end{array}$ & $\begin{array}{l}\text { (i) } \\
\text { (ii) }\end{array}$ & $\begin{array}{l}\text { effective }[58] \\
\text { effective }[59,60]\end{array}$ & $\begin{array}{l}\text { (i) } \\
\text { (ii) }\end{array}$ & $\begin{array}{l}\text { ineffective [61] } \\
\text { phase II: results not appeared yet [62] }\end{array}$ \\
\hline
\end{tabular}

YM872. YM872 significantly decreased infarct volume, ameliorated the neurological deficit score in a rat embolic stroke model [59] and was neuroprotective by decreasing loss of cortical tissue and cerebral edema after traumatic brain injury [60].

\section{Clinical Output}

ZK 200775. The AMPA antagonist ZK 200775 transiently worsened the neurological condition of patients with acute ischemic stroke. The results showed significant adverse (neuronal dysfunction, glial cell toxicity, sedation) effects in patients with acute stroke [61].

YM872. A phase II trial started in 2000 in which 24hour infusions of YM872 were given within $6 \mathrm{~h}$ after stroke onset. The diminution of ischemic lesion volume is measured by magnetic resonance imaging 28 days after the infusion has been given, and neurological function and disability scores are assessed at follow-up visits through day 90 of the study. Results have not been published yet [62] (table 1).

\section{Phase III Trials}

Neuroprotective drugs in the development pipeline are summarized below (table 2).

\section{Hypothermia (Cooling Effect)}

Hypothermia is one of the most promising neuroprotective strategies currently under clinical investigation. It consists of cooling down the brain temperature. Hypothermia has shown significant preclinical efficacy in animal models of cerebral ischemia [63] and has been shown to be feasible in acute stroke patients using either surface 
Table 2. Brief overview of ongoing phase III trials of neuroprotective agents

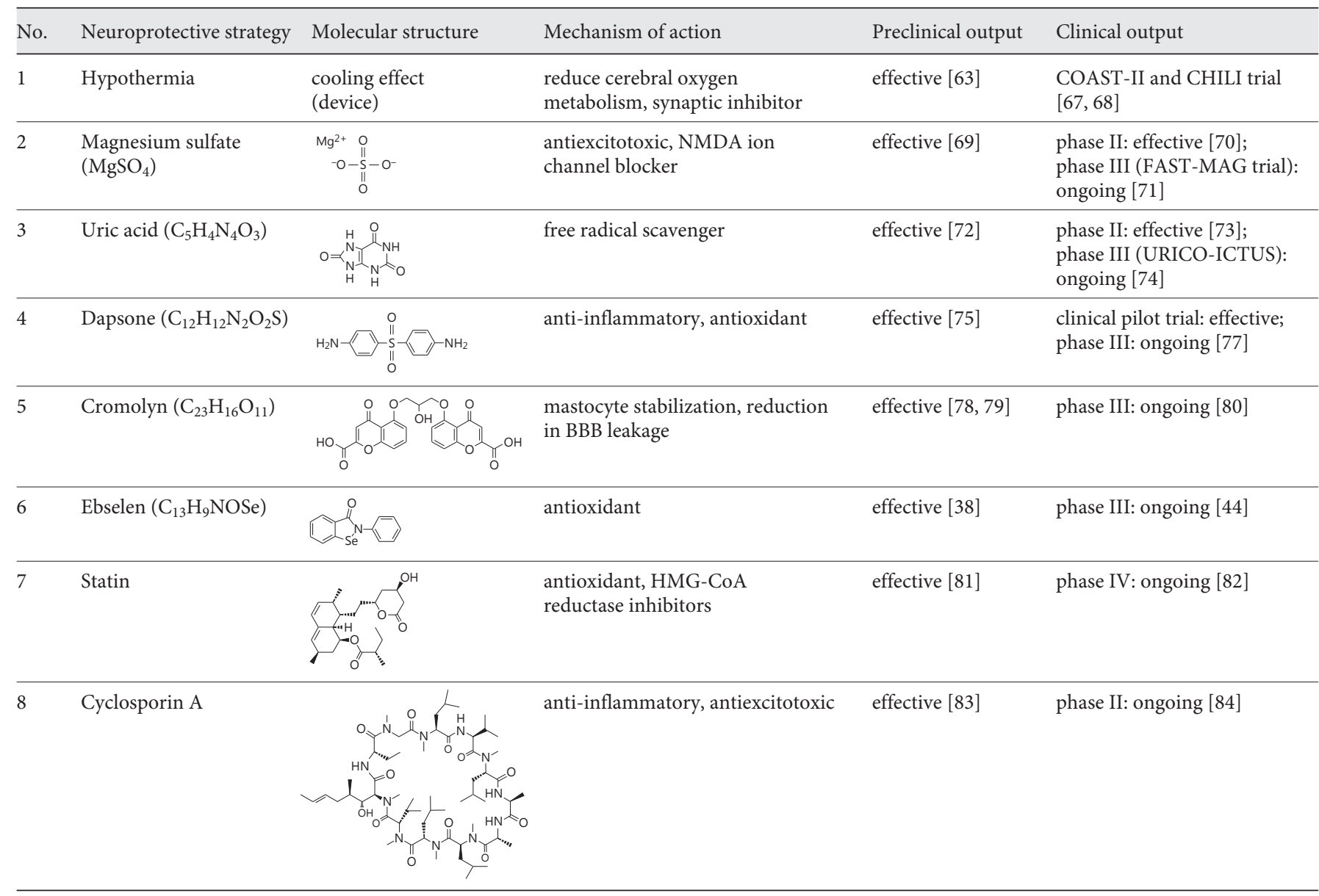

cooling or endovascular cooling [64, 65]; it is currently being investigated in both safety and efficacy trials: the COAST-II (Cooling in Acute Stroke), the CHILI (Controlled Hypothermia in Large Infarction) and the EuroHYP (European Stroke Research Network for Hypothermia)-1 trials $[66,67]$.

\section{Magnesium Sulfate}

Magnesium has demonstrated its neuroprotective effect in animal studies [68] as well as in a phase II study on stroke patients [69]. Magnesium had failed to show a significant effect on the primary end point or on any secondary end point in a previous phase III trial [70]. Currently, the FAST-MAG (Field Administration of Stroke Therapy - Magnesium) trial includes 1,700 stroke patients receiving a dose of $4 \mathrm{~g}$ (intravenously) over $15 \mathrm{~min}$, followed by a maintenance infusion of $16 \mathrm{~g}$ over $24 \mathrm{~h}$ after arrival at the hospital; it was started in January 2005 and is still in progress [71].

Drug Therapy and Stroke
Uric Acid

Uric acid showed its efficacy in animal studies [72] and was safe in a phase II trial [73]. The ongoing phase III trial URICO-ICTUS (Efficacy Study of Combined Treatment with Uric Acid and rt-PA in Acute Ischemic Stroke) was started in June 2011 to assess the clinical efficacy of uric acid administration in acute ischemic stroke patients treated with rt-PA within $4.5 \mathrm{~h}$ after stroke onset and is supposed to be completed in December 2013 [74].

\section{Dapsone}

Dapsone has been safe and beneficial in animal studies [75] and a clinical pilot study with 30 patients [76]. A phase III trial using a dose of $250 \mathrm{mg}$ (intravenously) administered within $12 \mathrm{~h}$ after onset is still in progress [77].

\section{Cromolyn}

Cromolyn has been very effective in reducing brain edema and BBB permeability in animal models of stroke 
$[78,79]$. A phase III clinical trial of acute ischemic stroke is still going on [80].

\section{Statins}

Statins (rosuvastatin) significantly protected the brain from ischemic stroke in mice [81]. Another statin, simvastatin, is tested in a phase IV study, started in 2009, including 340 patients. Results are still awaited [82].

\section{Cyclosporin A}

Cyclosporin A was neuroprotective in a permanent middle cerebral artery occlusion and homolateral transient common carotid artery occlusion model of rodents [83]. Phase II is in progress [84] (table 2).

\section{Discussion}

Stroke or cerebral ischemia is not only affecting public health but also posing a big threat by the social and economic burden it imposes on society. The higher rates of incidence, mortality and DALY in low- and middle-income countries are a matter of concern. New neurotherapeutic agents are urgently required to reduce the incidence as well as to treat the aftermath of stroke. However, despite the encouraging results from preclinical studies, stroke continues to be a big question mark for both neu- roscientists and clinicians. To date, thousands of neuroprotective agents have proved successful in experimental studies, but no new treatment has shown to be effective since t-PA was approved in 1996. The discrepancy between animal models and stroke occurring in humans tells a story of positive output of preclinical studies and of failure of clinical studies. Our past experience with stroke research increased our understanding of the epidemiology and pathophysiology of stroke, but we should focus on well-planned strategies: how to prevent injury due to reperfusion, and which is more beneficial - single drug administration or combined drug therapy for multiple targets in the brain. The novel approach should include increased blood restoration and increased survival rates of neurons in the penumbra region. Several agents are currently in clinical trials and they may fulfill the promises of neuroprotection. Before moving to clinical trials, drugs should be re-evaluated based on animal studies. Awareness programs should be implemented, especially in developing countries, so that people who are at great risk of stroke visit medical health institutes frequently. Translating bench success to the bedside has been discouraging. Despite the successful story of preclinical trials, there is still a need to establish animal models resembling the human disease, so that the translation of results from preclinical studies to clinical practice can be improved.

\section{References}

1 Mackay J, Mensah G: The Atlas of Heart and Stroke. Geneva, World Health Organization, 2004.

-2 The World Health Organization MONICA Project (monitoring trends and determinants in cardiovascular disease): a major international collaboration. WHO MONICA Project Principal Investigators. J Clin Epidemiol 1988;41:105-114.

-3 Writing Group Members, Lloyd-Jones D, Adams RJ, Brown TM, Carnethon M, Dai S, de Simone G, Ferguson TB, Ford E, Furie K, Gillespie C, Go A, Greenlund K, Haase N, Hailpern S, Ho PM, Howard V, Kissela B, Kittner S, Lackland D, Lisabeth L, Marelli A, McDermott MM, Meigs J, Mozaffarian D, Mussolino M, Nichol G, Roger VL, Rosamond W, Sacco R, Sorlie P, Roger VL, Thom T, WasserthielSmoller S, Wong ND, Wylie-Rosett J: Heart disease and stroke statistics - 2010 update: a report from the American Heart Association. Circulation 2010;121:e46-e215.

4 Murray CJL, Lopez AD: The Global Burden of Disease: A Comprehensive Assessment of Mortality and Disability from Diseases, Inju- ries, and Risk Factors in 1990 and Projected to 2020. Global Burden of Disease and Injury Series, book 1. Cambridge, Harvard UP, 1996.

5 Edvinsson L, Krause DN: Cerebral Blood Flow and Metabolism. Philadelphia, Lippincott Williams \& Wilkins, 2002.

6 Caplan L: Caplan's Stroke: A Clinical Approach. Philadelphia, Saunders Elsevier, 2009.

7 Asahi M, Wang X, Mori T, Sumii T, Jung JC, Moskowitz MA, Fini ME, Lo EH: Effects of matrix metalloproteinase- 9 gene knock-out on the proteolysis of blood-brain barrier and white matter components after cerebral ischemia. J Neurosci 2001;21:7724-7732.

8 Kincses ZT, Vecsei L: Pharmacological therapy in Parkinson's disease: focus on neuroprotection. CNS Neurosci Ther 2011;17:345-367.

$\checkmark 9$ Durukan A, Tatlisumak T: Acute ischemic stroke: overview of major experimental rodent models, pathophysiology, and therapy of focal cerebral ischemia. Pharmacol Biochem Behav 2007;87:179-197.

-10 O'Collins VE, Macleod MR, Donnan GA, Horky LL, van der Worp BH, Howells DW:
1,026 experimental treatments in acute stroke. Ann Neurol 2006;59:467-477.

11 Gladstone DJ, Black SE, Hakim AM: Toward wisdom from failure: lessons from neuroprotective stroke trials and new therapeutic directions. Stroke 2002;33:2123-2136.

12 Cheng YD, Al-Khoury L, Zivin JA: Neuroprotection for ischemic stroke: two decades of success and failure. NeuroRx 2004;1:36-45.

13 Camerlingo M, Salvi P, Belloni G, Gamba T, Cesana BM, Mamoli A: Intravenous heparin started within the first 3 hours after onset of symptoms as a treatment for acute nonlacunar hemispheric cerebral infarctions. Stroke 2005;36:2415-2420.

14 Zhang ZG, Lü TS, Yuan HY: Neuroprotective effects of ultra-low-molecular-weight heparin in vitro and vivo models of ischemic injury. Fundam Clin Pharmacol 2011;25:300-303.

15 Zhang ZG, Sun X, Zhang QZ, Yang H: Neuroprotective effects of ultra-low-molecularweight heparin on cerebral ischemia/reperfusion injury in rats: involvement of apoptosis, inflammatory reaction and energy metabolism. Int J Mol Sci 2013;14:1932-1939. 
16 Mary V, Wahl F, Uzan A, Stutzmann JM: Enoxaparin in experimental stroke: neuroprotection and therapeutic window of opportunity. Stroke 2001;32:993-999.

17 Study on Continuous Intravenous of Unfractionated Heparin (UFH) to Treat Progressive Cerebral Infarction (UHPCI). 2011. http:// clinicaltrials.gov/ct2/show/NCT01378000.

$\checkmark 18$ Kase CS, Albers GW, Bladin C, Fieschi C, Gabbai AA, O’Riordan W, Pineo GF: Neurological outcomes in patients with ischemic stroke receiving enoxaparin or heparin for venous thromboembolism prophylaxis: subanalysis of the Prevention of VTE after Acute Ischemic Stroke with LMWH (PREVAIL) study. Stroke 2009;40:3532-3540.

-19 Nonaka Y, Tsuruma K, Shimazawa M, Yoshimura S, Iwama T, Hara H: Cilostazol protects against hemorrhagic transformation in mice transient focal cerebral ischemia-induced brain damage. Neurosci Lett 2009;452: $156-161$.

-20 Ding G, Jiang Q, Zhang L, Zhang ZG, Li L, Knight RA, Ewing JR, Wang Y, Chopp M: Analysis of combined treatment of embolic stroke in rat with r-tPA and a GPIIb/IIIa inhibitor. J Cereb Blood Flow Metab 2005;25: 87-97.

-21 Lee YS, Bae HJ, Kang DW, Lee SH, Yu K, Park JM, Cho YJ, Hong KS, et al: Cilostazol in Acute Ischemic Stroke Treatment (CAIST Trial): a randomized double-blind non-inferiority trial. Cerebrovasc Dis 2011;32:65-71.

-22 Shinohara Y, Katayama Y, Uchiyama S, Yamaguchi T, Handa S, Matsuoka K, Ohashi Y, et al: Cilostazol for prevention of secondary stroke (CSPS 2): an aspirin-controlled, double-blind, randomised non-inferiority trial. Lancet Neurol 2010;9:959-968.

-23 Han SW, Lee SS, Kim SH, Lee JH, Kim GS, Kim OJ, Koh IS, et al: Effect of Cilostazol in Acute Lacunar Infarction Based on Pulsatility Index of Transcranial Doppler (ECLIPse): a multicenter, randomized, double-blind, placebocontrolled trial. Eur Neurol 2013;69:33-40.

24 Uchiyama S, Sakai N: Cilostazol-Aspirin Therapy against Recurrent Stroke with Intracranial Artery Stenosis. 2006. http://clinicaltrials.gov/show/NCT00333164.

-25 Pancioli AM, Broderick J, Brott T, Tomsick T, Khoury J, Bean J, del Zoppo G, et al: The combined approach to lysis utilizing eptifibatide and rt-PA in acute ischemic stroke: the CLEAR stroke trial. Stroke 2008;39:32683276.

26 Pancioli AM, Adeoye OM: Study of the Combination Therapy of rt-PA and Eptifibatide to Treat Acute Ischemic Stroke (CLEAR-ER). 2009. http://clinicaltrials.gov/show/NCT00894803.

$\checkmark 27$ Adams HP Jr, Effron MB, Torner J, Dávalos A, Frayne J, Teal P, Leclerc J, Oemar B, et al: Emergency administration of abciximab for treatment of patients with acute ischemic stroke: results of an international phase III trial - Abciximab in Emergency Treatment of Stroke Trial (AbESTT-II). Stroke 2008;39:8799.
28 SPS3 Investigators, Benavente OR, Hart RG, McClure LA, Szychowski JM, Coffey CS, Pearce LA: Effects of clopidogrel added to aspirin in patients with recent lacunar stroke. $\mathrm{N}$ Engl J Med 2012;367:817-825.

29 Lee KY: Comparison of Triflusal and Clopidogrel Effect in Secondary Prevention of Stroke Based on the Cytochrome P450 2C19 Genotyping (MAESTRO). 2010. http://clinicaltrials.gov/ct2/show/NCT01174693.

30 Tissue plasminogen activator for acute ischemic stroke. The National Institute of Neurological Disorders and Stroke rt-PA Stroke Study Group. N Engl J Med 1995;333:15811587.

31 Lee KY, Kim DI, Kim SH, Lee SI, Chung HW, Shim YW, Kim SM, Heo JH: Sequential combination of intravenous recombinant tissue plasminogen activator and intra-arterial urokinase in acute ischemic stroke. AJNR Am J Neuroradiol 2004;25:1470-1475.

32 Gan X, Luo Y, Ling F, Ji X, Chen J, Ding Y: Outcome in acute stroke with different intraarterial infusion rate of urokinase on thrombolysis. Interv Neuroradiol 2010;16:290-296.

33 Lee RS, Ok YC, Lim JS, Lim BC, Cho KY, Lee MC: Outcome evaluation of intravenous infusion of urokinase for acute ischemic stroke. Chonnam Med J 2012;48:52-56.

34 Horn J, de Haan RJ, Vermeulen M, Luiten PG, Limburg M: Nimodipine in animal model experiments of focal cerebral ischemia: a systematic review. Stroke 2001;32:2433-2438.

35 Zhang J, Yang J, Zhang C, Jiang X, Zhou H, Liu M: Calcium antagonists for acute ischemic stroke. Cochrane Database Syst Rev 2012; 5:CD001928.

-36 Sydserff SG, Borelli AR, Green AR, Cross AJ: Effect of NXY-059 on infarct volume after transient or permanent middle cerebral artery occlusion in the rat: studies on dose, plasma concentration and therapeutic time window. Br J Pharmacol 2002;135:103-112.

37 Marshall JW, Duffin KJ, Green AR, Ridley RM: NXY-059, a free radical-trapping agent, substantially lessens the functional disability resulting from cerebral ischemia in a primate species. Stroke 2001;32:190-198.

-38 Sui H, Wang W, Wang PH, Liu LS: Protective effect of antioxidant ebselen (PZ51) on the cerebral cortex of stroke-prone spontaneously hypertensive rats. Hypertens Res 2005;28: 249-254.

39 Sena E, Wheble P, Sandercock P, Macleod M: Systematic review and meta-analysis of the efficacy of tirilazad in experimental stroke. Stroke 2007;38:388-394.

40 Zhang N, Komine-Kobayashi M, Tanaka R, Liu M, Mizuno Y, Urabe T: Edaravone reduces early accumulation of oxidative products and sequential inflammatory responses after transient focal ischemia in mice brain. Stroke 2005;36:2220-2225.
41 Lee BJ, Egi Y, van Leyen K, Lo EH, Arai K: Edaravone, a free radical scavenger, protects components of the neurovascular unit against oxidative stress in vitro. Brain Res 2010;1307. 22-27.

42 Lees KR, Zivin JA, Ashwood T, Davalos A Davis SM, Diener HC, Grotta J, Lyden P, Shuaib A, Hårdemark HG, Wasiewski WW, Stroke-Acute Ischemic NXY Treatment (SAINT I) Trial Investigators: NXY-059 for acute ischemic stroke. N Engl J Med 2006; 354:588-600.

43 Shuaib A, Lees KR, Lyden P, Grotta J, Davalos A, Davis SM, Diener HC, Ashwood T, Wasiewski WW, Emeribe U: NXY-059 for the treatment of acute ischemic stroke. N Engl J Med 2007;357:562-571.

44 Ebselen Trial - Phase III. 2009. http://www. strokecenter.org/trials/clinicalstudies/298.

45 van der Worp HB, Kappelle LJ, Algra A, Bär PR, Orgogozo JM, Ringelstein EB, Bath PM, van Gijn J, TESS Investigators, TESS II Investigators: The effect of tirilazad mesylate on infarct volume of patients with acute ischemic stroke. Neurology 2002;58:133-135.

46 Nakase T, Yoshioka S, Suzuki A: Free radical scavenger, edaravone, reduces the lesion size of lacunar infarction in human brain ischemic stroke. BMC Neurol 2011;11:39.

47 Mitta M, Goel D, Bansal KK, Puri P: Edaravone-Citicoline Comparative Study in Acute Ischemic Stroke (ECCS-AIS). J Assoc Physicians India 2012;60:36-38.

48 Sydserff SG, Cross AJ, Murray TK, Jones JA, Green AR: Clomethiazole is neuroprotective in models of global and focal cerebral ischemia when infused at doses producing clinically relevant plasma concentrations. Brain Res 2000;862:59-62.

49 Chaulk D, Wells J, Evans S, Jackson D, Corbett D: Long-term effects of clomethiazole in a model of global ischemia. Exp Neurol 2003; 182:476-482.

50 Lyden P, Shuaib A, Ng K, Levin K, Atkinson RP, Rajput A, Wechsler L, Ashwood T, Claesson L, Odergren T, Salazar-Grueso E, CLASSI/H/T Investigators: Clomethiazole Acute Stroke Study in Ischemic Stroke (CLASS-I): final results. Stroke 2002;33:122-128.

51 Miyabe M, Kirsch JR, Nishikawa T, Koehler RC, Traystman RJ: Comparative analysis of brain protection by $\mathrm{N}$-methyl-D-aspartate receptor antagonists after transient focal ischemia in cats. Crit Care Med 1997;25:10371043.

52 Grotta J, Clark W, Coull B, Pettigrew LC, Mackay B, Goldstein LB, Meissner I, Murphy D, LaRue L: Safety and tolerability of the glutamate antagonist CGS 19755 (Selfotel) in patients with acute ischemic stroke: results of a phase IIa randomized trial. Stroke 1995;26: 602-605.

53 Davis SM, Lees KR, Albers GW, Diener HC, Markabi S, Karlsson G, Norris J: Selfotel in acute ischemic stroke: possible neurotoxic effects of an NMDA antagonist. Stroke 2000;31: $347-354$ 
54 Schäbitz WR, Li F, Fisher M: The N-methyl-D-aspartate antagonist CNS 1102 protects cerebral gray and white matter from ischemic injury following temporary focal ischemia in rats. Stroke 2000;31:1709-1714.

55 Nategh M, Shaveisi K, Shabanzadeh AP, Sadr SSh, Parviz M, Ghabaei M: Systemic hyperthermia masks the neuroprotective effects of MK-801, but not rosiglitazone in brain ischaemia. Basic Clin Pharmacol Toxicol 2010; 107:724-729.

56 Kocaeli H, Korfali E, Oztürk H, Kahveci N, Yilmazlar S: MK-801 improves neurological and histological outcomes after spinal cord ischemia induced by transient aortic crossclipping in rats. Surg Neurol 2005;64(suppl 2):S22-S26, discussion S27.

57 Albers GW, Goldstein LB, Hall D, Lesko LM, Aptiganel Acute Stroke Investigators: Aptiganel hydrochloride in acute ischemic stroke: a randomized controlled trial. JAMA 2001; 286:2673-2682.

58 Turski L, Huth A, Sheardown M, McDonald F, Neuhaus R, Schneider HH, Dirnagl U, Wiegand F, Jacobsen P, Ottow E: ZK200775: a phosphonate quinoxalinedione AMPA antagonist for neuroprotection in stroke and trauma. Proc Natl Acad Sci USA 1998;95: 10960-10965.

59 Suzuki M, Sasamata M, Miyata K: Neuroprotective effects of YM872 coadministered with t-PA in a rat embolic stroke model. Brain Res 2003;959:169-172.

60 Furukawa T, Hoshino S, Kobayashi S, Asakura T, Takahashi M, Atsumi T, Teramoto A: The glutamate AMPA receptor antagonist, YM872, attenuates cortical tissue loss, regional cerebral edema, and neurological motor deficits after experimental brain injury in rats. J Neurotrauma 2003;20:269-278.

61 Walters MR, Kaste M, Lees KR, Diener HC, Hommel M, de Keyser J, Steiner H, Versavel M: The AMPA antagonist ZK 200775 in patients with acute ischaemic stroke: a doubleblind, multicentre, placebo-controlled safety and tolerability study. Cerebrovasc Dis 2005; 20:304-309.

62 A Study to Evaluate the Effects of YM872 on Stroke Lesion Volume in Acute Stroke Patients. 2002. http://clinicaltrials.gov/ct2/ show/NCT00044070.

-63 van der Worp HB, Sena ES, Donnan GA, Howells DW, Macleod MR: Hypothermia in animal models of acute ischaemic stroke: a systematic review and meta-analysis. Brain 2007;130:3063-3074.
64 de Georgia MA, Krieger DW, Abou-Chebl A, Devlin TG, Jauss M, Davis SM, Koroshetz WJ, Rordorf G, Warach S: Cooling for Acute Ischemic Brain Damage (COOL AID): a feasibility trial of endovascular cooling. Neurology 2004;63:312-317.

65 Hemmen TM, Raman R, Guluma KZ, Meyer BC, Gomes JA, Cruz-Flores S, Wijman CA, Rapp KS, Grotta JC, Lyden PD, ICTuS-L Investigators: Intravenous thrombolysis plus hypothermia for acute treatment of ischemic stroke (ICTuS-L): final results. Stroke 2010; 41:2265-2270.

66 Schwab S: Cooling plus Best Medical Treatment versus Best Medical Treatment Alone for Acute Ischaemic Stroke (EuroHYP 1). 2013. http://clinicaltrials.gov/show/ NCT01833312.

67 Macleod MR, Petersson J, Norrving B, Hacke W, Dirnagl U, Wagner M, Schwab S, European Hypothermia Stroke Research Workshop: Hypothermia for Stroke: call to action 2010. Int J Stroke 2010;5:489-492.

68 Marinov MB, Harbaugh KS, Hoopes PJ, Pikus HJ, Harbaugh RE: Neuroprotective effects of preischemia intraarterial magnesium sulfate in reversible focal cerebral ischemia. J Neurosurg 1996;85:117-124.

69 Bradford A, Lees K: Design of the Intravenous Magnesium Efficacy in Acute Stroke (IMAGES) trial. Curr Control Trials Cardiovasc Med 2000;1:184-190.

70 Muir KW, Lees KR, Ford I, Davis S, Intravenous Magnesium Efficacy in Stroke (IMAGES) Study Investigators: Magnesium for acute stroke (Intravenous Magnesium Efficacy in Stroke trial): randomised controlled trial. Lancet 2004;363:439-445.

71 Field Administration of Stroke Therapy Magnesium (FAST-MAG) Trial. 2003. http:// clinicaltrials.gov/show/NCT00059332.

72 Romanos E, Planas AM, Amaro S, Chamorro A: Uric acid reduces brain damage and improves the benefits of rt-PA in a rat model of thromboembolic stroke. J Cereb Blood Flow Metab 2007;27:14-20.

73 Amaro S, Soy D, Obach V, Cervera A, Planas AM, Chamorro A: A pilot study of dual treatment with recombinant tissue plasminogen activator and uric acid in acute ischemic stroke. Stroke 2007;38:2173-2175.
4 Amaro S, Cánovas D, Castellanos M, Gállego J, Martí-Fèbregas J, Segura T, Chamorro A: The URICO-ICTUS study, a phase 3 study of combined treatment with uric acid and rtPA administered intravenously in acute ischaemic stroke patients within the first $4.5 \mathrm{~h}$ of onset of symptoms. Int J Stroke 2010;5:325328.

75 Ríos C, Nader-Kawachi J, Rodriguez-Payán AJ, Nava-Ruiz C: Neuroprotective effect of dapsone in an occlusive model of focal ischemia in rats. Brain Res 2004;999:212-215.

76 Nader-Kawachi J, Góngora-Rivera F, SantosZambrano J, Calzada P, Ríos C: Neuroprotective effect of dapsone in patients with acute ischemic stroke: a pilot study. Neurol Res 2007;29:331-334.

77 Dapsone for Acute Ischemia Stroke Study (DAISY). 2010. http://clinicaltrials.gov/ show/NCT01144650.

78 Strbian D, Karjalainen-Lindsberg ML, Tatlisumak T, Lindsberg PJ: Cerebral mast cells regulate early ischemic brain swelling and neutrophil accumulation. J Cereb Blood Flow Metab 2006;26:605-612.

79 Strbian D, Tatlisumak T, Ramadan UA, Lindsberg PJ: Mast cell blocking reduces brain edema and hematoma volume and improves outcome after experimental intracerebral hemorrhage. J Cereb Blood Flow Metab 2007;27:795-802.

80 Treatment of Acute Stroke with Cromolyn (Single Dose). 2010. http://clinicaltrials.gov/ ct2/show/NCT01175525.

81 Prinz V, Laufs U, Gertz K, Kronenberg G, Balkaya M, Leithner C, Lindauer U, Endres $\mathrm{M}$ : Intravenous rosuvastatin for acute stroke treatment: an animal study. Stroke 2008;39: 433-438.

82 Montaner J, Ribó M, Jimenez C, Muñoz F, Canovas D, Krupinski J, Martinez-Zabaleta M, de la Torre Laviana FJ, Freijo M, Segura T, Arenillas J, Flores JM, Alonso F, Vallejo JM, Borrego FR, García JT, Martín AL, Anguiano YB, Roig XU, García FP, Mederos RD: Stroke Treatment with Acute Reperfusion and Simvastatin. 2010. http://clinicaltrials.gov/show/ NCT01073007.

83 Leger PL, de Paulis D, Branco S, Bonnin P, Couture-Lepetit E, Baud O, Renolleau S, Ovize M, Gharib A, Charriaut-Marlangue C: Evaluation of cyclosporine A in a stroke model in the immature rat brain. Exp Neurol 2011; 230:58-66.

84 Nighoghossian N: Neuroprotection Impact of Cyclosporin A in Cerebral Infarction (CsAStroke). 2012. http://clinicaltrials.gov/ show/NCT01527240. 